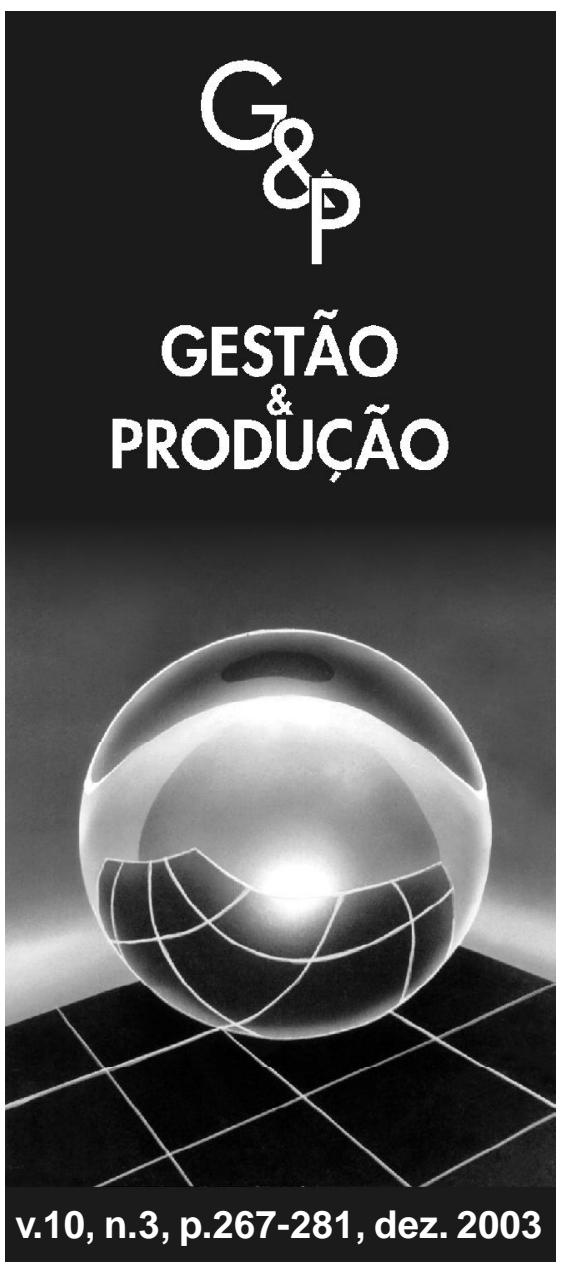

\title{
O PAPEL DAS SUBSIDIÁRIAS E A INTERNACIONALIZAÇÃO DAS ATIVIDADES TECNOLÓGICAS PELAS EMPRESAS TRANSNACIONAIS
} (ETNs)

\author{
Rogério Gomes \\ Departamento de Economia da Faculdade de \\ Ciências e Letras (FCL/CAr), Unesp \\ Pesquisador do Grupo de Estudos em \\ Economia Industrial (Geein), Universidade Estadual Paulista \\ (Unesp), Rodovia Araraquara-Jaú, km 1, CEP 14800-901, \\ Araraquara, SP, e-mail: rgomes@fclar.unesp.br
}

Recebido em 2/6/2003

Aceito em 27/11/2003

\section{Resumo}

Este estudo se propõe a analisar os mandatos das subsidiárias de empresas transnacionais (ETNs) no estrangeiro por intermédio dos mecanismos de alocação das atividades de pesquisa e desenvolvimento $(P \& D)$ entre os centros descentralizados de pesquisa. Iniciamos o trabalho com a apresentação de uma síntese das diferentes perspectivas encontradas na literatura econômica sobre a subordinação (ou condicionamentos) da autonomia administrativa e tecnológica das filiais. Tal síntese permite estabelecer uma hierarquia entre as subsidiárias e uma tipologia para evolução (retrocesso) de mandatos construída, principalmente, para as ETNs estruturadas em forma de rede corporativa. A seguir, a partir de pesquisas realizadas sobre as atividades dos laboratórios de $P \& D$ da indústria de equipamentos de telecomunicações no Brasil, procuramos mostrar que: a) a descentralização das atividades tecnológicas é um fato que não está restrito apenas aos países centrais; $b$ ) as tecnologias de informação permitiram que as subsidiárias no país se integrassem aos laboratórios centrais das ETNs, dando-lhes condições de desenvolver e participar de outras atividades tecnológicas, além das tradicionais funções de adaptação de processo e de produtos.

Palavras-chave: empresas transnacionais, mandatos de subsidiárias, internacionalização e descentralização de pesquisa e desenvolvimento, evolução das capacidades tecnológicas em países em desenvolvimento. 


\section{Introdução}

$\mathrm{D}$ urante um longo tempo, grande parte da literatura sobre o processo de internacionalização das ETNs (e da globalização) assumiu que as vantagens específicas à propriedade eram desenvolvidas unicamente dentro da matriz corporativa que, por meio da transferência de tecnologia, garantia o desenvolvimento das subsidiárias no estrangeiro. Mais recentemente, alguns pesquisadores perceberam que o crescimento por meio dos recursos internos à empresa é um processo que também se efetiva no interior das filiais no exterior, auxiliando a sede da multinacional na criação de vantagens competitivas. As diversas perspectivas da dinâmica desse processo conduziram à construção de modelos que procuraram refletir os novos papéis das subsidiárias.

Enquanto tradicionalmente a transferência de tecnologia era interpretada como um fluxo unidirecional do centro para as subsidiárias, na perspectiva da rede corporativa, a dispersão da atividade tecnológica passa a ser uma estratégia da ETN, que visa a adquirir e acumular vantagens pelo esquadrinhamento global de novos recursos para inovação. Nesse sentido, as subsidiárias são formalmente orientadas para o mercado local e crescentemente incorporadas à rede internacional da ETN.

A diversificação tecnológica passou a ser uma importante característica das ETNs, na medida em que as subsidiárias no estrangeiro têm assumido papéis específicos nas funções de $\mathrm{P} \& \mathrm{D}$, seja na ênfase continuada ao processo local de inovação, seja no desenvolvimento de um capital organizacional que permite que as ETNs integrem as atividades tecnológicas das unidades dispersas. A crescente dispersão geográfica dos ativos estratégicos impulsiona a capacitação das filiais no estrangeiro, tanto em relação ao crescimento horizontal, das comunicações interfronteiras nacionais, quanto no sentido vertical, de utilização sistemática do conhecimento tecnológico das diversas bases da organização. Por isso, o objeto das pesquisas tem crescentemente se movido dos benefícios estratégicos da utilização de recursos emergentes de uma subsidiária estrangeira particular em direção às vantagens associadas à contínua integração.

Este estudo se propõe a analisar o mandato das subsidiárias de ETNs no estrangeiro por meio dos mecanismos de alocação das atividades de P\&D para os centros de pesquisa descentralizados. Iniciamos o trabalho com a apresentação de uma síntese das diferentes perspectivas encontradas na literatura econômica sobre a subordinação (ou condicionamento) administrativa e, especialmente, tecnológica das filiais. Tal síntese permite estabelecer uma hierarquia entre as subsidiárias e uma tipologia para evolução (retrocesso) de mandatos construída, principalmente, para as ETNs organizadas por meio de rede corporativa. A seguir, a partir de pesquisas realizadas sobre as atividades dos laboratórios de $\mathrm{P} \& \mathrm{D}$ da indústria de equipamentos de telecomunicações no Brasil, procuramos mostrar que: a) a descentralização das atividades tecnológicas é um fato que não está restrito apenas aos países centrais; e b) as tecnologias de informação permitiram que as subsidiárias no país se integrassem aos laboratórios centrais das ETNs, dando-lhes condições de desenvolver e participar de outras atividades tecnológicas, além das tradicionais funções de adaptação de processo e de produtos.

\section{A evolução subsidiária}

O conceito de evolução das subsidiárias origina-se de um processo temporal de acumulação (ou redução) de recursos e capacidades (ativos) que, por essência, não é único. Uma subsidiária pode tornar-se maior e mais especializada (ou ter seu tamanho reduzido) em razão de diferentes motivações (busca de recursos, capacidades e eficiência ou apenas de novos mercados para explorar suas vantagens) ou a partir dos modos de entrada no mercado local - investimento, aquisição ou joint venture. Indiferente aos motivos e aos modos de entrada da empresa multinacional em determinado país, esta seção se concentra nos processos genéricos que se iniciam com o Investimento Direto Estrangeiro (IDE) em filiais de propriedade parcial ou total, que cons- 
tituem os principais casos da literatura. Aqui, a subsidiária é entendida como instituição que adiciona valor no estrangeiro e executa uma única atividade (manufatura) ou toda a cadeia de valor. Assim, o papel exercido por uma subsidiária dentro de uma corporação está estreitamente ligado a sua capacidade de adicionar valor. Esse suposto permite, portanto, distintas trajetórias evolutivas entre as unidades de uma mesma corporação, inclusive em uma mesma região.

\subsection{As abordagens teóricas}

A literatura sobre a evolução de subsidiárias das empresas multinacionais é fragmentada e com uma parcela substancial da discussão concentrada nos aspectos administrativos. Mais recentemente, particularmente na década de 1990, os estudos se voltaram para analisar o papel cumprido pelas filiais dentro das redes multinacionais. Porém, as mudanças nesses papéis têm sido pouco abordadas, seja pelo recorte metodológico do estudo, seja pela concepção de que, em geral, esses papéis são meras atribuições do comando corporativo. Birkinshaw \& Hood (1998), analisando o desenvolvimento das subsidiárias, apontam para três condicionantes gerais que podem interagir ao longo do tempo para determinar as funções das filiais de uma ETN. Esses condicionantes constituem um processo pendular que é resultado das decisões tomadas pela sede e pela subsidiária, muitas vezes conflituosas. Essa discussão, além de propiciar breve exposição das diferentes abordagens teóricas sobre as relações entre as ETNs e suas filiais e os papéis destas últimas, também permite explicitar algumas das formas de internacionalização da atividade tecnológica, tema das seções posteriores.

As três condicionantes e os principais modelos que emanam de cada uma delas são apresentados a seguir.

I. Atribuição do comando central: a primeira interpretação é aquela que considera as decisões tomadas pelo comando corporativo como condicionantes fundamentais para determinar as atividades de dada subsidiária. Do ponto de vista histórico, esses estudos caminham dos modelos dos anos 50 e 60 de subsidiárias, enquanto réplicas em miniatura das matrizes (Vernon, 1966), em direção aos de manufaturas racionalizadas e especialistas em produtos das duas décadas seguintes (Hood \& Young, 1983). Essa linha de abordagem também pode ser encontrada nos estudos produzidos nos Estados Unidos, notadamente, em modelos que interpretam o crescimento das filiais como um processo seqüencial de recursos comprometidos e de capacidades construídas (Jarillo \& Martinez, 1990). É possível agrupar em duas grandes visões teóricas a perspectiva das subsidiárias como um instrumento da ETN que atua somente em atenção aos imperativos do centro de decisões:

a) O modelo do ciclo de vida do produto: o esquema elaborado por Vernon (1966) pode ser pensado em três estágios. No primeiro, a ETN produz e vende o produto no próprio mercado de origem e exporta para alguns países no estrangeiro. Com a maturação da tecnologia do produto, a redução dos custos de produção ganha importância e a competição no estrangeiro passa a ser uma ameaça. No estágio seguinte, a empresa multinacional instala uma unidade de produção no estrangeiro para atender principalmente ao mercado do país em questão. Os contínuos melhoramentos na qualidade e os aperfeiçoamentos incrementais podem fazer com que a produção da filial passe a ser exportada para a matriz, revertendo o fluxo comercial que originou o modelo. Em um hipotético estágio final, os custos de produção do país no estrangeiro deixam de ser competitivos e a produção é transferida para outro país onde eles são comparativamente menores.

A relevância desse modelo está na ênfase dada ao papel da subsidiária, que evolui em direção às atividades de maior valor adicionado. Inicialmente, o mercado local é abastecido pela adaptação das tecnologias de processo e produto para as especificidades da região, transferidas da sede tecnológica. Posteriormente, a exportação do produto para o país de origem da empresa poderia, algumas vezes, alterar a função da 
subsidiária, que passaria, então, a contribuir para o desenvolvimento do produto. Se, por um lado, o modelo de Vernon é de grande utilidade analítica para a compreensão dos estágios iniciais da evolução da subsidiária, por outro, estabelece uma relação de profunda dependência da filial com o comando corporativo. Essa característica é uma importante limitação do esquema de ciclo de vida do produto, pois desconsidera tanto o papel que uma unidade corporativa pode ter na estrutura mundial da ETN quanto as possibilidades de decisões autônomas.

b) O processo de internacionalização: oriundo da teoria comportamental da firma, o modelo que entende a internacionalização como um processo parte de hipóteses sobre as limitações cognitivas e de comportamento do administrador individual para entender como a firma se move para além das fronteiras nacionais (Johanson \& Vahlne, 1977). Esse processo é explicado em termos de relações recíprocas entre: a) o nível de conhecimento e o atual grau de comprometimento da empresa com o mercado estrangeiro; e b) as decisões além daquelas relacionadas ao mercado. Por exemplo, a decisão de ampliar a operação de uma manufatura é um compromisso com base na avaliação das fraquezas e das forças (conhecimento) do mercado e um desejo de elevar a qualidade dos investimentos no país (compromisso de mercado). Cada uma dessas decisões conduz a um comprometimento crescente e à maior compreensão do ambiente local. Assim, o desenvolvimento da subsidiária é alcançado pela interação cíclica entre investimento e aprendizagem.

II. A escolha da subsidiária: essa perspectiva se baseia na capacidade de decisão autônoma, ainda que limitada, da administração da filial em relação a suas próprias atividades, diferentemente da relação bilateral e de dependência entre subsidiária e matriz das interpretações anteriores. Nessa abordagem coexistem duas correntes teóricas com considerável poder explicativo da evolução da subsidiária. Ambas apontam para importantes aspectos do papel das capacidades implícitas às subsidiárias e enfatizam a função destas últimas como elemento da rede corpo- rativa multinacional. Tal enfoque é, portanto, importante alternativa analítica para entender a ação das subsidiárias.

Alguns dos estudos dessa linha teórica observam que as filiais que obtiveram mandato mundial para produtos devem creditá-lo a suas capacidades diferenciadas e a uma forte relação com a matriz. Outras pesquisas notaram que as estratégias das matrizes, em resposta às mudanças nas condições macroeconômicas do ambiente comercial, moldaram a trajetória das subsidiárias em direção à especialização. Também, os trabalhos que procuraram detectar as atividades e os tipos de laboratórios de P\&D dentro da ETN obtiveram conclusões similares sobre a escolha das subsidiárias (Papanastassiou \& Pearce, 1994; Cantwell, 1995; Pearce \& Papanastassiou, 1999). Nestes últimos, por intermédio dos laboratórios de P\&D associados à produção, as subsidiárias tendem a evoluir a partir de suas próprias iniciativas em direção a atividades de maior valor adicionado. Mesmo as pesquisas elaboradas sob a ótica do comando corporativo (item anterior), voltadas para o desenvolvimento organizacional, apresentam evidências de que as subsidiárias estão construindo recursos especializados e obtendo reconhecimento por suas capacidades diferenciadas.

Os diferentes enfoques e os numerosos casos relatados na literatura indicam que o caminho específico de desenvolvimento das subsidiárias é influenciado pela ação empresarial de seus administradores. Dentro dessa condicionante podem ser agrupadas duas grandes visões teóricas:

a) $O$ modelo de rede da ETN: a grande contribuição dessa abordagem está em reconhecer que as vantagens específicas à propriedade não estão restritas apenas ao país de origem da empresa, mas podem ser adquiridas e construídas pelas filiais em diferentes regiões. Por princípio, essa perspectiva admite que uma subsidiária pode se mover vertical e horizontalmente; transitar entre os vários níveis hierárquicos da corporação multinacional, podendo até mesmo alcançar posições extremas, como a de liderança em determinadas áreas de negócios; ou ter seu fim decretado pelo comando corporativo. No lugar de hierarquias 
rígidas, quando comparada a outras interpretações, a ETN é estruturada como uma rede multiorganizacional de instituições com vínculos relativamente fracos, os quais permitem que as filiais gozem de certa liberdade para desenvolver suas características próprias e específicas.

A importância da visão da evolução da subsidiária inserida em um contexto de rede multinacional se expressa também pelos aspectos da realidade. Admitir que as subsidiárias possuem capacidades e recursos inerentes às suas atividades, das quais as demais unidades da ETN são dependentes, além de ultrapassar o limite da relação meramente dual e dependente filialmatriz-filial, também estabelece uma estrutura organizacional em que cada elo pode ter atribuições diferenciadas dentro da rede. Em outras palavras, aceitar tal pressuposto é assumir a possibilidade de distintos mandatos entre filiais na execução de determinadas atividades dentro da corporação. A evolução da filial é, portanto, tomada como um processo orgânico e cumulativo, construído por meio do crescimento (e declínio) de recursos distintos e valiosos para a subsidiária. Nesse sentido, à medida que uma subsidiária amplia seu estoque de recursos e capacidades, sua dependência se reduz. Contudo, essa evolução é restringida pela capacidade de crescimento dos recursos e também por outras instituições, especialmente a matriz, que usam seu poder de coação para impor sua orientação.

No modelo tradicional de relações matrizfilial, o controle do comando corporativo pode, teoricamente, ser exercido com maior intensidade. Essa questão, que é fundamental para a estrutura do modelo e que já suscitou muito debate, perde muito de sua força quando a eficiência dos mecanismos de controle corporativo é minorada ou quando as empresas se estruturam por intermédio de relações do tipo rede, descritas anteriormente. Neste último caso, o contexto teórico prevê, além de uma dimensão geográfica mais abrangente, agora global, profunda ampliação das relações comerciais, internas e externas à rede, que afetam as condições de controle.
Esses fatos, por si mesmos, seriam suficientes para explicar por que grande parte das transações deixam de ser realizadas sem o tradicional papel de intermediação da matriz. Mas, adicionalmente, há também as mudanças qualitativas nas atividades das unidades no estrangeiro - e, portanto, nos mandatos -, agindo no sentido de reforçar o enfraquecimento do controle do comando corporativo.

b) O processo decisório em organizações complexas: assim como no processo de internacionalização apresentado anteriormente, esse enfoque tem por hipótese básica a racionalidade limitada do administrador. Alguns trabalhos analisaram explicitamente a evolução das subsidiárias, interessados em compreender o limite entre o controle exercido pelo comando corporativo sobre suas filiais e o ponto em que estas últimas passam a se beneficiar de seu próprio crescimento (Prahalad \& Doz, 1981). Nosso interesse particular é o reconhecimento de que: o comportamento estratégico por vezes ocorre abaixo do nível superior da administração; o comportamento autônomo configura um processo interno de crescimento das subsidiárias, o qual não pode ser plenamente controlado pelas diretrizes do comando corporativo. Em consequiência, na maioria das vezes, o processo evolutivo da filial é apenas monitorado ou imprecisamente controlado. Assim, o gozo de alguma autonomia permite que as subsidiárias tomem certas iniciativas visando, por exemplo, a obter mandatos de produtos mundiais.

III. Determinismo do ambiente local: nessa abordagem, o papel da subsidiária é entendido como função das restrições e das oportunidades no mercado local. Alguns pesquisadores entendem que cada unidade corporativa opera em um ambiente único, próprio, que determina ou restringe sua atividade (Bartlett \& Ghoshal, 1990). A natureza do espaço local, definido por clientes, competidores, fornecedores, etc., tem importante influência nas atividades empreendidas pela filial (Krugman, 1991). 
Em síntese, os argumentos convergem para a proposição de que a subsidiária opera sob um conjunto de condições específicas para o qual ela está adaptada no sentido de aumentar sua eficácia. A maioria dos estudos dessa abordagem analisa as relações entre a subsidiária e o ambiente local dentro de uma perspectiva estática. Praticamente inexistem trabalhos considerando a dinâmica das relações entre o desenvolvimento local/regional e a evolução da subsidiária e entre eles e o estrangeiro. Ainda que as subsidiárias sejam um importante condutor de tecnologias e desenvolvimento de habilidades para a economia local, dada sua capacidade de adotar e aplicar níveis crescentemente sofisticados de tecnologia da ETN, poucos estudos dessa perspectiva consideram explicitamente a importância do setor externo como uma força do processo de evolução da subsidiária.

\section{O papel das subsidiárias na rede corporativa}

Dependendo da forma pela qual se deseja analisar a distribuição das funções corporativas internacionalmente, cada uma das abordagens anteriores apresenta características relevantes que podem ser levadas em consideração. A perspectiva adotada neste trabalho é a da ETN como instituição estruturada em rede mundial. Nela, cada subsidiária é entendida como uma unidade semi-autônoma, capaz de tomar suas próprias decisões, ainda que condicionadas pelas ações do comando corporativo e pelas oportunidades e restrições percebidas no ambiente local. Por este recorte analítico procuramos privilegiar as capacidades dinâmicas inerentes ao desenvolvimento das subsidiárias.

Uma pesquisa realizada por Pearce (1999), com as subsidiárias estrangeiras no Reino Unido, procurou relacionar os papéis dessas unidades segundo a importância relativa das operações executadas. Os resultados, apresentados na Tabela 1, contribuem para reforçar a opção analítica e auxiliar na avaliação dos mandatos.

As subsidiárias foram classificadas segundo o alcance geográfico da atividade realizada na unidade, tomada como medida indireta da intensidade tecnológica em quatro categorias (Pearce, 1999), a saber:

a) Papel focado no mercado local: mesmo sendo arcaica na competição global contemporânea, a forma tradicional deve ser parte de um processo de evolução para novas posições da hierarquia, pois quando elas possuem laboratórios de $\mathrm{P} \& \mathrm{D}$ associados, defendem um papel mais ambicioso para o futuro.

Tabela 1 - Mandatos exercidos pelas subsidiárias estrangeiras.

\begin{tabular}{|c|c|c|c|c|c|}
\hline \multirow{2}{*}{$\begin{array}{c}\text { Papel da subsidiária } \\
\text { (dimensão geográfica das } \\
\text { atividades) }\end{array}$} & \multicolumn{4}{|c|}{ Tipo de papel exercido pela subsidiária (\%) } & \multirow{2}{*}{$\begin{array}{c}\text { Nível de } \\
\text { significância } \\
\text { estatística }(\%)\end{array}$} \\
\hline & Único & Predominante & Secundário & $\begin{array}{l}\text { Não exerce } \\
\text { o papel }\end{array}$ & \\
\hline $\begin{array}{l}\text { a) Voltada para o mercado local } \\
\text { (Reino Unido) }\end{array}$ & 8,0 & 37,0 & 27,0 & 27,6 & ns \\
\hline $\begin{array}{l}\text { b) Voltada para o mercado regional } \\
\text { (Europa) }\end{array}$ & 3,2 & 46,5 & 21,6 & 28,6 & 5,0 \\
\hline $\begin{array}{l}\text { c) Compartilhar a produção da rede } \\
\text { regional (Europa) para } \\
\text { exportação em âmbito mundial }\end{array}$ & 1,1 & 6,1 & 22,7 & 70,2 & $\mathrm{~ns}$ \\
\hline $\begin{array}{l}\text { d) Desenvolver, produzir e } \\
\text { comercializar novos produtos } \\
\text { para o mercado local (Reino } \\
\text { Unido) e regional (Europa) }\end{array}$ & 8,7 & 27,2 & 34,2 & 29,9 & 1,0 \\
\hline
\end{tabular}

Obs.: 1. respostas de questionário remetido às subsidiárias estrangeiras no Reino Unido. 2. ns: não significativo.

Fonte: Elaborado a partir de dados apresentados por Pearce (1999). 
b) Papel na rede de fornecimento regional: apesar de a especialização na produção e na exportação de partes da gama de produtos bem estabelecida da ETN, as operações dessas subsidiárias estão mais integradas ao grupo do que as do caso anterior. As necessidades de suporte são substituídas por requisitos de criação que garantem uma unidade de P\&D. Nessa categoria há a esperança de ampliar o escopo de desenvolvimento de produtos.

c) Papel estreitamente integrado na rede de fornecimento regional para produção e exportação de componentes $e$ partes em âmbito mundial: pode representar um papel tecnologicamente inferior ao proporcionar pouco escopo para o $\mathrm{P} \& \mathrm{D}$ corporativo ou também pode significar responsabilidades na criação se os componentes produzidos pela subsidiária estão associados à rede que envolve extenso desenvolvimento de produtos.

d) Papel de desenvolver, produzir e vender para o mercado regional e local (Reino Unido e Europa) novos produtos, além da gama de produtos do grupo: a subsidiária exerce um mandato com dimensão mundial ou regional.

Além da condição de plataforma regional para exportações de produtos globais (item c; $70 \%$ declaram não exercer essa tarefa), os dados revelam que as subsidiárias realizam, interna e concomitantemente, como prioridade ou não, as demais atividades das outras três categorias. Essa função multitarefa está de acordo com uma das hipóteses deste trabalho: as empresas exploram ativos e, principalmente, procuram adquirir novas vantagens por intermédio das unidades corporativas.

As duas indicações declaradas como mais relevantes (e estatisticamente significativas: itens b e d da Tabela 1) mostram estruturas de redes regionalmente integradas, com funções hierarquicamente diferenciadas. O papel do tipo 6 aponta também para atividades que incorporam alguma geração de tecnologia (adaptação com desenvolvimento de produtos para as exigências particulares de cada país da região), ainda limitada, mas com perspectivas de expansão futura. Em outras palavras, as subsidiárias trabalham, com alguma autonomia, procurando ampliar suas capacitações para reforçar os atuais mandatos e conquistar novos.

A categoria d confirma a capacidade de algumas subsidiárias executarem tarefas com elevado conteúdo tecnológico, mesmo quando elas não têm concessão específica para isso - as unidades que declaram realizar, como papel predominante e secundário, o desenvolvimento de novos produtos é superior a 60\%. Quando analisado em conjunto com outros resultados da Tabela 1, esse porcentual se traduz em forte evidência de que as atividades com densidade tecnológica são realizadas em subsidiária com diferentes papéis (apenas 30\% dos entrevistados afirmam não exercer a função d de alguma forma).

Em suma, um status mais elevado na hierarquia corporativa não isenta uma unidade de funções de menor densidade tecnológica. Da mesma maneira, uma subsidiária com papel inferior pode, se tiver desenvolvido as capacidades necessárias (muito provavelmente de forma autônoma), exercer funções superiores àquelas que seriam consideradas habituais. Esses argumentos têm, ainda, outra importante implicação: o desenvolvimento de produtos está emergindo como um motivo decisivo para a internacionalização do P\&D nas subsidiárias das ETNs, como também confirmado pela Tabela 2 .

Por outro lado, a Tabela 2 mostra que os fatores apontados como os mais importantes para uma possível redução do mandato de uma subsidiária são o desempenho econômico da subsidiária (situação financeira interna negativa) ou do grupo (como resultado da racionalização do grupo em resposta às condições de mercado) $\mathrm{e}$ as decisões do comando de reestruturação corporativa ligadas à reformulação do programa tecnológico (decisão da matriz de limitar o papel do laboratório). Fica explícito que a perda de funções pela subsidiária dentro do grupo é ditada pela matriz. Mesmo em casos de elevadas competências tecnológicas, há certa vulnerabilidade das unidades no estrangeiro às decisões externas guiadas pelos princípios do programa global.

Cada unidade cumpre (e estabelece) determinadas funções dentro da rede multinacional, que 
se expressam nas áreas de negócios das quais ela participa. Uma subsidiária só é capaz de realizar as atividades comerciais que estão sob sua responsabilidade porque possui (desenvolveu) recursos e capacidades mínimas requeridos para tais funções. As capacidades podem, portanto, ser analisadas em termos de mercados servidos, de produtos manufaturados, das áreas funcionais cobertas, tecnologias de apoio, ou quaisquer combinações desses elementos. O papel atribuído pelo comando corporativo caracteriza o mandato que uma subsidiária adquiriu para executar as atuais funções, específicas dentre aquelas existentes na complexa teia de relações e atividades da ETN.

\section{Tabela 2 - Fatores que podem influenciar o desenvolvimento ou causar redução do papel dos laboratórios de P\&D.}

\begin{tabular}{lcccccc}
\hline \multicolumn{7}{c}{ A. Fatores que podem influenciar o desenvolvimento do papel dos laboratórios de P\&D } \\
\hline País/região & A & Tipo de influência & (porcentagem das respostas) & \\
& B & C & D & E & F \\
EUA & 23,1 & 38,5 & 15,4 & 38,5 & 23,1 & 92,3 \\
Japão & 66,7 & 11,1 & 11,1 & 55,6 & 33,3 & 55,6 \\
Europa & 26,7 & 60,0 & 20,2 & 46,7 & 20,0 & 80,0 \\
Total & 41,3 & 34,8 & 15,2 & 47,8 & 26,1 & 73,9 \\
A: disponibilidade local de pessoal científico & & & \\
B: apoio financeiro do governo (taxas, incentivos, etc.) & & \\
C: pressionados pelas políticas do governo \\
D: desejo de desenvolver um produto diferenciado para o mercado local da subsidiária \\
E: apoiar o papel crescentemente independente da subsidiária local nas atividades do grupo \\
F: apoiar o papel crescente do laboratório local no atividade científica do grupo
\end{tabular}

\begin{tabular}{|c|c|c|c|c|c|c|c|}
\hline \multicolumn{8}{|c|}{ B. Fatores que podem causar redução do papel dos laboratórios de P\&D } \\
\hline \multirow[t]{2}{*}{ País/região } & \multicolumn{7}{|c|}{ Tipo de influência (porcentagem das respostas) } \\
\hline & A & $\mathrm{B}$ & $\mathrm{C}$ & $\mathrm{D}$ & $\mathrm{E}$ & $\mathrm{F}$ & G \\
\hline EUA & 16,7 & 75,0 & 66,7 & 66,7 & 75,0 & 66,7 & 0,0 \\
\hline Japão & 31,6 & 31,6 & 78,9 & 21,1 & 57,9 & 42,1 & 10,5 \\
\hline Europa & 18,8 & 62,5 & 75,0 & 50,0 & 81,3 & 75,0 & 12,5 \\
\hline Total & 23,4 & 53,2 & 74,5 & 42,6 & 70,3 & 59,6 & 8,5 \\
\hline \multicolumn{8}{|c|}{ A: carência local de pessoal científico } \\
\hline \multicolumn{8}{|c|}{ B: aspectos adversos do ambiente financeiro (impostos crescentes) } \\
\hline \multicolumn{8}{|c|}{ C: situação financeira interna negativa (lucros decrescentes, aumento de salários, etc.) } \\
\hline \multicolumn{8}{|c|}{ D: Pressões desfavoráveis das políticas do governo } \\
\hline \multicolumn{8}{|c|}{ E: Decisão da matriz de limitar o papel do laboratório } \\
\hline \multicolumn{8}{|c|}{$\begin{array}{l}\text { F: Como resultado da racionalização do grupo em resposta às condições de mercado (recessão, aumento } \\
\text { da competição, etc.) }\end{array}$} \\
\hline G: Menor $\mathrm{n}$ & de $d$ & apo & açc & dus & bs1 & & \\
\hline
\end{tabular}

Obs.: 1. Respostas a questionário remetido às subsidiárias estrangeiras no Reino Unido.

2. Os consultados foram convidados a endossar qualquer fator que considerasse influente.

3. Pesquisa realizada entre 1992 e 1994.

4. Esta tabela tem por origem a mesma pesquisa da Tabela 1.

Fonte: Elaborado a partir de Pearce \& Papanastassiou (1999), Tabelas 7 e 8, p. 37-38. 
A acumulação de capacidades e recursos em uma subsidiária não é um processo necessariamente interligado ou de desenvolvimento concomitante ao das demais. Ainda que os recursos fossem exclusivamente repassados por uma unidade da rede corporativa (por exemplo, a matriz) e uma outra procurasse reproduzir identicamente a rotina da primeira, ambas seriam diferentes (Nelson \& Winter, 1982). Os recursos são, principalmente, o resultado da acumulação interna de capacidades e, portanto, dependentes do desenvolvimento criativo e de suas novas combinações. Nesse contexto, as atividades de uma unidade corporativa espelham, ao menos em parte, seu nível de especialização.

Os mandatos e as capacidades de uma filial também não precisam, necessariamente, se mover juntos. A evolução (ou declínio) de uma subsidiária resulta de um processo movido por mecanismos em que elas adquirem e concentram (ou dissipam) capacidades ao longo do tempo. Essas habilidades estão em parte estocadas nas rotinas organizacionais internas, em parte provêm das influências de outras subsidiárias ou da corporação como um todo e, em parte, são resultado de fatores relacionados ao ambiente local. Nesse sentido, a trajetória de desenvolvimento de uma subsidiária é absolutamente única e, em razão de suas particularidades geográficas e históricas, a configuração de suas capacidades distingue-se daquela da matriz e das demais filiais. $O$ compartilhamento das capacidades entre unidades corporativas não é trivial, pela rigidez existente na transferência de conhecimento (ao menos no caso do conhecimento tácito) de uma subsidiária para outra. Porém, mesmo não sendo idênticas, algumas subsidiárias têm capacidades com perfis similares. Essa similaridade é a origem da disputa por mandatos dentro da rede multinacional, sejam eles novos ou já existentes.

Um novo mandato (em qualquer direção da escala hierárquica), como reconhecimento de novas habilidades conquistadas (ou perdidas), pode não ser efetivado pela corporação. A abordagem tradicional justifica esse fenômeno por meio de falhas nos elos relacionais entre a subsidiária e o comando central da empresa.
Porém, a literatura recente, especialmente aquela relacionada à economia internacional e da inovação, considera que a causa freqüente dessa "inércia” está na estratégia corporativa global (ou regional). Nesta última interpretação, ainda que tenha alcançado níveis de especialização para gozar de status superior dentro da ETN, se a subsidiária (ou a região) não está inserida na dinâmica mais geral dos planos de negócios de longo ou médio prazo da empresa, então, o mais provável é que seu mandato não se altere ou até, diante de uma possível necessidade de reestruturação da corporação, seja reduzido. De qualquer forma, seja por incentivos diretos da administração central (por exemplo, investimento em expansão), seja pelos mecanismos indiretos (competição externa e interna), a estrutura de rede da ETN incentiva a constante ampliação dos ativos ou das vantagens existentes, permitindo que a empresa se mantenha competitiva.

A maioria dos mandatos é contestável, sobretudo quando os recursos subjacentes a eles têm por característica a mobilidade regional. Essa mobilidade latente, a competição interna (para crescimento da subsidiária pela absorção de maiores fatias do mercado interno corporativo ou para obtenção de mandatos) e a disputa externa (entre fornecedores, competidores, clientes e ambiente local) são os motores do processo de evolução da subsidiária e, portanto, importante fonte para ampliação de capacidades da ETN. O reconhecimento dessas capacidades e seu aproveitamento na rede corporativa, mesmo que às custas de crescente especialização, são os principais instrumentos de persuasão para a concessão de um novo mandato.

$\mathrm{O}$ aumento (atrofia) de capacidades e o estabelecimento (redução) de compromissos (aqui interpretados como mandatos) foram utilizados por Birkinshaw \& Hood (1998) na construção de uma tipologia do processo evolutivo das subsidiárias. As cinco situações possíveis são sintetizadas a seguir:

\section{a) Processo de investimento dirigido pela matriz (aquisição de mandato/estímulo de capacidades):} estabelecimento de uma filial cujo mandato foi 
atribuído pela matriz e que ainda não desenvolveu suas próprias capacidades. Os critérios decisórios são da matriz e não do local.

b) Processo de ampliação de mandato dirigido pela subsidiária (mantém mandato/melhoria das capacidades): estratégia dos administradores da subsidiária quando percebem uma oportunidade (em novos negócios) para ganhar ou melhorar o mandato. Após a construção de capacidades, a subsidiária procura ampliar seu mandato por meio de: 1 . iniciativa de pesquisa dirigida para novas oportunidades de mercado, tanto local como corporativo; 2 . procura de uma oportunidade específica de mercado e do desenvolvimento das capacidades apropriadas para preenchê-las; 3 . proposta direta à matriz (que julgará a concessão) para ampliação do mandato.

c) Reforço do mandato dirigido pela subsidiária (mantém mandato/estimulando capacidades): como no caso anterior, o processo dirigido inteiramente pela subsidiária está relacionado à competição entre outra(s) irmã(s) corporativa(s) ou a competidor(es) externo(s). Se o processo for efetivo, resultando em menores custos e/ou qualidade e/ou melhorias nos serviços, o mandato da subsidiária será reforçado.

d) Desinvestimento dirigido pela matriz (simétrico ao primeiro caso): originado pela decisão da matriz de racionalizar as operações internacionais e/ou pela retirada de certos negócios visando a se concentrar no núcleo dos negócios. A decisão e a avaliação dependem do comando corporativo, pois as capacidades são imediatamente perdidas.

e) Atrofia em razão de negligência da subsidiária: a unidade torna-se cada vez menos competitiva, em decorrência de, por exemplo, falhas na administração ou resultados financeiros desfavoráveis, desmotivando as pressões para redução dos custos ou para melhorias nos serviços.

No conjunto, as situações anteriores delineiam um sistema mais dinâmico do que a interpretação tradicional, tanto em termos de mobilidade dos mandatos quanto na competição entre as sub- sidiárias no mercado interno corporativo. As subsidiárias são "julgadas" em termos do nível relativo de suas capacidades e não em termos absolutos. Uma subsidiária pode manter o mandato, mas, se suas capacidades se distanciam da estratégia tecnológica da companhia, as habilidades de outras unidades serão evidenciadas, por exemplo, quando confrontadas em um programa de racionalização dos negócios corporativos.

\section{O papel das subsidiárias brasileiras de indústrias de equipamentos de telecomunicação}

A ênfase nas atividades tecnológicas é um aspecto marcante da concorrência entre as grandes empresas globais de equipamentos de telecomunicações. A atual conformação do setor no Brasil é caracterizada pela presença predominante dessas corporações do setor. Uma parte expressiva dessas empresas estrangeiras (quatro das nove ETNs que detêm a quase totalidade do mercado mundial) alocou na região de Campinas as mais importantes atividades tecnológicas do País (Gomes \& Roselino, 2001; Suzigan et al., 2001).

A grande maioria das ETNs do setor está se concentrando cada vez mais nas atividades de concepção e design. Parte significativa das atividades de produção, montagem e, em alguns casos, de logística de fornecimento e distribuição do produto das subsidiárias brasileiras do setor foi transferida para empresas prestadoras de serviços de manufatura. Para as subsidiárias do setor na região resta, como uma de suas principais funções corporativas, o desenvolvimento de soluções para produtos determinados (Gomes, 2003).

A inovação de produtos da indústria de informação e comunicação, responsável direta ou indiretamente por uma infinidade de inovações em outros setores, depende cada vez mais do desenvolvimento de softwares embarcados aproximadamente $50 \%$ do preço de um produto da indústria de informática está relacionado aos softwares embarcados (Roselino \& Gomes, 
2000). A própria inovação é, em essência, crescentemente um novo software. Em muitos dos antigos laboratórios subsidiários, principalmente onde a manufatura foi transferida para terceiros, e em grande número das novas unidades de $\mathrm{P} \& \mathrm{D}$, as atividades estão voltadas principalmente para o desenvolvimento de softwares. Essa função também está ocupando papel central no segmento de telecomunicações e é crescentemente determinante das funções desempenhadas pelos equipamentos. Os estudos sobre o setor apontam para uma forte tendência de comoditização do hardware, fato que reservaria aos softwares quase todas as características diferenciadoras dos produtos.

As empresas de equipamentos de telecomunicação da região de Campinas voltam seus esforços tecnológicos locais ao desenvolvimento de softwares para centrais telefônicas, estações rádiobase ou terminais celulares (25\% dos empregados exercem atividades de $\mathrm{P} \& \mathrm{D}$ e, destes, $90 \%$ estão ligados a projetos de desenvolvimento de sistemas e programas informáticos (Suzigan et al., 2001). Em geral, as unidades estabelecidas no local possuem posição privilegiada dentro da distribuição das atividades corporativas de $\mathrm{P} \& \mathrm{D}$, integrando a estratégia global da corporação em uma especialidade na qual suas capacidades são reconhecidas (Gomes, 2003).

Aparentemente, a forma mais usual de alocação das atividades de $\mathrm{P} \& \mathrm{D}$ pelo comando corporativo é a distribuição dessas funções por meio de "licitação" no mercado interno à corporação. Uma vez que o comando central tenha decidido levar adiante determinado projeto para um novo produto, ele convoca uma reunião com os diversos representantes das subsidiárias no estrangeiro que possuem capacitação técnica para realizar tal projeto. Após serem anunciadas a proposta e as especificações para desenvolvimento do produto, cada um dos diversos participantes interessados em disputar a execução da tarefa propõe prazos e preços para a entrega do produto. $\mathrm{O}$ vencedor é aquele que apresenta as melhores condições, aquele que, em geral, dá maior ênfase ao prazo de entrega do que ao preço da solução.
No caso de uma subsidiária de uma ETN com sede na América do Norte, por exemplo, a unidade brasileira tem mandato de âmbito mundial para a tecnologia TDMA de telefonia celular. Ainda que essa tecnologia esteja distante da denominada "de última geração", atualmente a filial no País é responsável por todas as soluções que se fizerem necessárias em relação a ela. Esse status foi adquirido em virtude da competência demonstrada na solução de problemas relativos à tecnologia ocorridos no passado.

As funções realizadas pelas unidades de $\mathrm{P} \& \mathrm{D}$ têm âmbito internacional, são bastante desatreladas do cotidiano produtivo e executadas em associação com outros laboratórios do mesmo tipo. Por outro lado, porém, a atualidade da função tecnológica não está inserida no "núcleo duro" da pesquisa corporativa. Mesmo que essas unidades de P\&D não estejam engajadas na estratégia de longo prazo da ETN, elas podem, graças à dimensão internacional de parte de suas atividades, procurar se manter atualizadas em relação às tecnologias que vigoram na $\mathrm{ETN}, \mathrm{o}$ que lhes permite avançar em termos tecnológicos e de mandato subsidiário.

A subsidiária que detém o mandato mundial da "antiga" tecnologia TDMA tem planos para migrar para a CDMA, mais avançada do ponto de vista tecnológico (a opção pela tecnologia de última geração Global System Mobile - GSM dependeria de uma análise de investimento da própria unidade). O interessante é que as dificuldades apontadas para montagem do laboratório para esse fim específico não provêm de uma restrição imposta pelo comando da corporação. Pelo contrário, os impedimentos dizem respeito à legislação do País em relação à importação dos equipamentos necessários; as empresas alegam demora por parte das autoridades no julgamento do cumprimento da Lei de Informática como o principal obstáculo à liberação das importações necessárias a seus laboratórios.

O desempenho a contento da prerrogativa de desenvolver determinado produto, conquistada em uma "licitação corporativa", pode representar, posteriormente, o usufruto dos direitos sobre os 
aperfeiçoamentos e sobre as assessorias eventualmente prestadas para outras unidades no estrangeiro. Os direitos sobre uma tecnologia podem ser gozados, muito provavelmente, durante todo o ciclo de vida do produto. Se, por um lado, isso pode significar temporariamente certa vantagem em relação às demais filiais alhures, por outro, também pode atrelar a subsidiária a uma tecnologia que está, cedo ou tarde, fadada ao "envelhecimento". Nestas circunstâncias, a subsidiária poderá viver longo processo de estagnação tecnológica ou, até mesmo, decadência.

Quanto maior o sucesso de uma subsidiária na formulação de novas soluções, maior seu "estoque de capacidades endógenas" e mais renomado deverá se tornar seu laboratório. No entanto, como determinada função tecnológica pode extrapolar o próprio papel de um laboratório, o questionamento dos mandatos está sempre presente. Se isso está correto, então a mobilidade em termos de papéis subsidiários está posta. Alguns repetidos sucessos na solução de "pequenos" problemas, ou "apenas" uma única idéia revolucionária, podem levar o laboratório a ascender dentro da hierarquia da ETN.

\section{Comentários finais}

Neste estudo, a subsidiária da ETN é concebida como uma instituição, parte de uma rede de relações comerciais, que adiciona valor ao executar uma ou várias atividades da cadeia de valor da corporação. A conseqüência direta dessa perspectiva é que as diferentes unidades de uma mesma empresa, nas diversas regiões do planeta, podem apresentar distintas trajetórias evolutivas. Assim como no modelo de evolução da subsidiária que atribui ao comando corporativo o centro de todas as decisões, esse entendimento permite que o mandato da subsidiária possa evoluir em direção às atividades de maior valor adicionado. Porém, diferentemente desse modelo, com algum grau de autonomia.

$\mathrm{Na}$ interpretação aqui adotada, como nos modelos de escolha da subsidiária, cada subsidiária tem, mesmo que condicionada, a oportunidade de escolher a própria trajetória, por usufruir de alguns graus de liberdade (variáveis) na determinação de seu futuro. A perspectiva de comportamento autônomo parece ser uma poderosa força que atua no sentido do desenvolvimento planejado, não fortuito, dos recursos e, principalmente, das capacidades. Ao mesmo tempo, a autonomia parcial permite fundar o suporte do comando corporativo como condição necessária, mas não suficiente, para o crescimento dirigido das subsidiárias. Por outro lado, também é possível supor que a falta de ação dos administradores pode conduzir a um processo de atrofia e eventual desaparecimento da própria subsidiária ou apenas de parte de suas capacidades. Assim, na perspectiva de semi-autonomia, o processo evolutivo é capaz de caracterizar, com maior grau de realismo, as diferenças e as mudanças nos mandatos das subsidiárias.

A argumentação aqui desenvolvida também incorpora algumas hipóteses dos modelos de determinismo do ambiente local, que vinculam o desenvolvimento regional e a evolução da subsidiária, especialmente os aspectos sobre a transferência de conhecimento. O desenvolvimento da subsidiária é, assim, movido tanto pelo dinamismo do ambiente de negócios local quanto por sua habilidade em acessar os recursos e as habilidades da ETN.

A acumulação de capacidades e recursos em uma subsidiária não é um processo necessariamente interligado ou de desenvolvimento concomitante ao das demais. Os recursos são, principalmente, o resultado da acumulação interna de capacidades e, portanto, dependentes do desenvolvimento criativo e de suas novas combinações.

Os mandatos e as capacidades de uma filial também não precisam, necessariamente, se mover juntos. Em razão de suas particularidades geográficas e históricas, a trajetória de desenvolvimento de uma subsidiária, como vimos, é absolutamente única, e a configuração de suas capacidades se distingue da matriz e das demais filiais. Mostramos também que, mesmo não sendo idênticas, algumas subsidiárias têm capacidades com perfis similares. Essa similaridade é a origem da disputa por mandatos dentro da rede 
multinacional, sejam eles novos ou existentes. Entretanto, a maioria dos mandatos é contestável. A competição interna à empresa e a disputa externa, entre os demais elementos da rede corporativa, são os motores do processo de evolução da subsidiária e, portanto, importante fonte para ampliação de capacidades da ETN.

O processo evolutivo aqui esboçado admite que as capacidades das subsidiárias podem ser estimuladas e atualizadas diante da competição com outras unidades internas e externas ao grupo empresarial. Na estrutura do modelo, as filiais possuem certo nível de autonomia na tomada de decisão, fato que as capacita a perseguir ou tomar iniciativas de ampliação e reforço de seu mandato. A maior autonomia da unidade pode ser conseqüência de um processo histórico peculiarmente fértil (nível local) e das relações com a matriz (nível rede), ambos, muitas vezes, bastante relacionados. Por outro lado, para o comando corporativo, os procedimentos de alocação competitiva de recursos podem ser considerados mecanismos para melhorar a capacidade da ETN em alocar mandatos de forma mais apropriada.

Entre os mecanismos de distribuição internacional das atividades tecnológicas na indústria de equipamentos de telecomunicações, um importante aspecto sobressai da estratégia global de direcionamento dos esforços de P\&D das ETNs: a existência de forte concorrência interna à ETN, incentivada pelo comando da empresa, dentre as diversas unidades, pelo desenvolvimento de projetos de natureza tecnológica. Dessa maneira, são reforçados a criação e o desenvolvimento de capacidades internas às subsidiárias, que, por outro lado, incentivam a autonomia das unidades no estrangeiro. Ao mesmo tempo, a ETN estrutura uma ampla rede com o intuito de apropriação de diferentes ativos tecnológicos, em qualquer lugar onde eles possam ser gerados e melhor explorados em termos econômicos.

O aporte de capital para um novo laboratório de P\&D voltado para softwares é bastante reduzido comparativamente ao direcionado para outros objetivos. O risco relativo aos pesados investimentos iniciais, como, por exemplo, para as unidades de pesquisa pura ou básica da indústria química, é significativamente menor naquelas unidades. Mesmos os investimentos para construção de centros de desenvolvimento de hardware dentro da própria indústria de informação e comunicação são mais onerosos do que os necessários à instalação de laboratórios para desenvolvimento de software. Esse aspecto é responsável por algumas das peculiaridades destes últimos.

A reduzida necessidade de investimento inicial dos laboratórios de softwares tanto reduz as "barreiras à entrada" quanto representa pequenas "barreiras à saída", o que dá a esses laboratórios uma característica muito especial: a grande mobilidade internacional. Nesse sentido, como há pouca ou nenhuma "indivisibilidade dos ativos fixos", e se não estiverem presentes fortes barreiras institucionais, o principal determinante do investimento dos laboratórios voltados para a produção de softwares é o capital humano qualificado. Em outras palavras, esses centros se caracterizam por serem intensivos em trabalho especializado, o que outorga à ETN amplo campo de ação para captura de ativos específicos ao local, em qualquer região do globo em que ele estiver disponível com qualidade e por baixo custo de apropriação. Não é por acaso que diversas unidades desse tipo de laboratório estão instaladas em vários países emergentes que conquistaram reputação internacional no desenvolvimento de softwares, como, por exemplo, a Índia e, em ascensão, o Brasil.

Por fim, a partir da discussão anterior, transparece importante característica da descentralização das atividades de P\&D. É comum que as funções tecnológicas relativas à concepção do produto sejam retidas centralmente. No setor de telecomunicações, a definição da arquitetura do sistema lógico (software) é determinada pelos laboratórios hierarquicamente superiores. $\mathrm{Na}$ reunião de "licitação" para determinação das subsidiárias encarregadas pelo desenvolvimento de cada uma das partes do produto, a estrutura e a organização lógica de funcionamento de todo o sistema estão previamente determinadas pela direção de $\mathrm{P} \& \mathrm{D}$. As unidades no estrangeiro 
estão, em sua maioria, inseridas nos esforços tecnológicos da corporação e realizam localmente etapas ou partes de projetos globais. Entretanto, o grau de liberdade das iniciativas tecnológicas das subsidiárias é normalmente delimitado pela dimensão do módulo do projeto que lhe cabe.

Se o painel que traçamos é verossímil e representativo de parte das atuais estratégias de dispersão das atividades tecnológicas das ETNs, então estamos vivenciando um processo de fortes mudanças nessas estratégias. A internacionalização da P\&D está deixando de ser um fenômeno restrito à esfera produtiva e limitado aos países centrais. Por mecanismos sub-reptícios, decorrentes do processo de globalização, da luta concorrencial entre os oligopólios mundiais e da subcontratação da manufatura, a descentralização das atividades tecnológicas vem ganhando cada vez mais uma dinâmica própria.

As subsidiárias das ETNs nas economias em desenvolvimento que apresentam capacidades tecnológicas específicas, outrora excluídas da internacionalização consistente da $\mathrm{P} \& \mathrm{D}$, agora estão sendo agregadas a esse processo de descentralização. Ao menos nos casos dos "centros de excelência em softwares", essa integração parece estar sendo processada em condições similares às ocorridas historicamente com os países centrais de reconhecida reputação em determinada área do conhecimento científico.

\section{Referências Bibliográficas}

BARTLETT, C. A.; GHOSHAL, S. Managing innovation in the transnational corporation. In: BARTLETT, C. A.; DOZ, Y.; HEDLUND, G. Managing in global firm. Routledge, 1990.

BIRKINSHAW, J.; HOOD, N. Multinational subsidiary evolution: capability and charter change in foreignowned subsidiary companies. Academy of Management Review, v. 23, n. 4, p. 773-795, 1998.

CANTWELL, J. The Globalization of technology: what remains of the cycle model? Cambridge Journal of Economics, v. 19, p. 155-174, 1995.

GOMES, R.; ROSELINO, J. E. Comportamento tecnológico das empresas: o setor de equipamentos de telecomunicações. In: FURTADO, J. et al. Comportamento tecnológico das empresas. Pesquisa em convênio FINEP/FUNDUNESP, Araraquara, 2001 (mimeo).

GOMES, R. A internacionalização das atividades tecnológicas pelas empresas transnacionais: elementos de organização industrial da economia da inovação. 2003. Tese (Doutorado) - IE/Unicamp.

HOOD, N.; YOUNG, S. Multinational investment strategies. London: HMSO, 1983.

JARILLO, J. C.; MARTINEZ, J. I. Different roles for subsidiaries: the cases of multinational corporations. Strategic Management Journal, v. 11, p. 501-512, 1990.
JOHANSON, J.; VAHLNE, J. E. The internationalization process of the firm: a model of knowledge development and increasing foreign market commitments. Journal of International Studies, v. 8, p. 23-32, 1977.

KRUGMAN, P. Geography and trade. Leuven, Belgica: Leuven University Press, 1991.

NELSON, R.; WINTER, S. An evolutionary theory of economic change. Cambridge: Harvard University Press, 1982.

PAPANASTASSIOU, M.; PEARCE, R. D. The internationalization of research and development by Japanese enterprises. $R \& D$ Management, v. 24, p. 155-165, 1994.

PEARCE, R. D.; PAPANASTASSIOU, M. Overseas R\&D and strategic evolution of MNEs: evidence from laboratories in the UK. Research Policy, v. 28, p. 23-41, 1999.

PEARCE, R. D. Decentralized R\&D and strategic competitiveness: globalised approaches to generation and use of technology in multinational enterprises (MNEs). Research Policy, v. 28, p. 157-17, 1999.

PRAHALAD, C. K.; DOZ, Y. L. An approach to strategic control in MNCs. Sloan Management Review, v. 22 (summer), p. 5-13, 1981. 
ROSELINO, J. E.; GOMES, R. Limites e possibilidades do Brasil nas configurações produtivas globalizadas - software. Relatório de pesquisa. Convênio GEEIN/IPEA. Araraquara, Campinas, abr. 2000.

SUZIGAN, W. et al. Inovação e difusão tecnológica em sistemas produtivos locais: evidências e sugestões de políticas. Relatório final da pesquisa Perspectiva de Reestruturação das Políticas de
Financiamento do Desenvolvimento Tecnológico no Brasil, convênio FINEP/FUNDAP (versão preliminar), jul. 2001.

VERNON, R. Investimento externo e comércio internacional no ciclo do produto. 1966. In: SAVASINI, A. A. et al. (Orgs.). Economia internacional. São Paulo: Saraiva, 1979. (Série Ampec de leituras de economia.)

\title{
THE SUBSIDIARY MANDATE AND THE INTERNATIONALIZATION OF TECHNOLOGICAL ACTIVITIES BY TRANSNATIONAL ENTERPRISES
}

\begin{abstract}
This paper tries to analyze mandates of Transnational Enterprises (TNEs) subsidiaries in the foreigner through the mechanisms of allocating activities of $R \& D$ (Research and Development) between decentralized centers of research. We initiate the work by presenting a synthesis of the different perspectives found in economic literature on the subordination (or conditionings) administrative and technological of the subsidiaries. Such synthesis allows us to establish a hierarchy between subsidiaries and a typology for evolution (retrocession) of mandates constructed, mainly, for the TNEs that are structuralized in form of a corporative network. Then, from researches on the activities of laboratories of $R \& D$ in the industry of telecommunications equipment in Brazil, we tried to show that: a) the decentralization of the technological activities is a fact that is not restricted only to developed countries; $b)$ the information and communication technologies have allowed that the subsidiaries in the foreigner integrated themselves to the central laboratories of the TNEs giving them conditions to develop and to participate on other technological activities beyond the traditional functions of adapting process and products.
\end{abstract}

Keys words: transnational enterprise, subsidiary mandate, research and development internationalization and decentralization, evolution of technological capabilities in developing countries. 